OPEN ACCESS

Edited by:

Assunta Lombardi,

University of Naples Federico II, Italy

Reviewed by:

Lin Zhang,

Hubei University of Chinese

Medicine, China

Maria Moreno,

University of Sannio, Italy

${ }^{*}$ Correspondence: José María Moreno-Navarrete

jmoreno@idibgi.org

Hjalmar R. Bouma

h.r.bouma@umcg.n

Specialty section: This article was submitted to Integrative Physiology, a section of the journal Frontiers in Physiology

Received: 08 April 2021 Accepted: 15 June 2021

Published: 12 July 2021

Citation:

Moreno-Navarrete JM, Comas F de Jager $V$, Fernández-Real JM and Bouma HR (2021) Cecal Ligation and Puncture-Induced Sepsis Promotes Brown Adipose Tissue Inflammation Without Any Impact on Expression of

Thermogenic-Related Genes.

Front. Physiol. 12:692618.

doi: 10.3389/fphys.2021.692618

\section{Cecal Ligation and Puncture-Induced Sepsis Promotes Brown Adipose Tissue Inflammation Without Any Impact on Expression of Thermogenic-Related Genes}

\author{
José María Moreno-Navarrete ${ }^{1,2,3 *}$, Ferran Comas ${ }^{1,2}$, Vincent de Jager \\ José Manuel Fernández-Real ${ }^{1,2,3}$ and Hjalmar R. Bouma ${ }^{4,5 *}$ \\ 'Department of Diabetes, Endocrinology and Nutrition (UDEN), Hospital of Girona "Dr Josep Trueta" and Institut \\ d'Investigació Biomèdica de Girona (IdIBGi), Girona, Spain, ${ }^{2} \mathrm{CIBER}$ de la Fisiopatología de la Obesidad y Nutrición \\ (CIBERobn) (CB06/03/010), Girona, Spain, ${ }^{3}$ Department of Medicine, Universitat de Girona, Girona, Spain, ${ }^{4}$ Department of \\ Clinical Pharmacy and Pharmacology, University Medical Center Groningen, University of Groningen, Groningen, \\ Netherlands, ${ }^{5}$ Department of Internal Medicine, University Medical Center Groningen, University of Groningen, Groningen, \\ Netherlands
}

Background and Aims: The negative effects of chronic low-level inflammation on adipose tissue physiology have been extensively demonstrated, whereas the effects of acute inflammation are less studied. Here, we aimed to investigate the effects of sepsis-induced acute inflammation on gene expression markers of brown and white adipose tissue functionality.

Methods: Brown adipose tissue (BAT) and perirenal white adipose tissue (prWAT) gene expression markers were analyzed in cecal ligation and puncture (CLP)-induced sepsis mice model.

Results: CLP-induced sepsis attenuated expression of adipogenesis-related genes, in parallel to increased Tnf, I/6, and Ltf gene expression in prWAT. In contrast, CLP-induced sepsis resulted in increased expression of pro-inflammatory genes (II6, $L t f$, and $L b p)$ in BAT, without affecting expression of genes encoding for thermogenic activity.

Conclusion: Sepsis promotes both prWAT and BAT inflammation, associated with reduced adipogenesis-related gene expression in prWAT, without significant effects on BAT thermogenic genes.

Keywords: cecal ligation and puncture, inflammation, sepsis, brown adipose tissue, white adipose tissue

\section{INTRODUCTION}

Obesity is a low-level chronic inflammatory condition associated with adipose tissue dysfunction and insulin resistance mediated by decreased levels of adiponectin and increased proinflammatory cytokines (Klöting and Blüher, 2014). Adipose tissue dysfunction is characterized by increased inflammation and decreased adipogenesis (Klöting and Blüher, 2014; Carobbio et al., 2017). 
While adipose tissue dysfunction induced by chronic inflammation is well demonstrated (Klöting and Blüher, 2014; Acosta et al., 2016; Carobbio et al., 2017; Hotamisligil, 2017), the impact of acute inflammation on adipose tissue is not yet fully understood, in particular brown adipose tissue (BAT).

Acute inflammation induced by bariatric surgery results in increased expression of pro-inflammatory genes in parallel to decreased adipogenesis-related gene expression in both human subcutaneous and visceral fat depots (Ortega et al., 2016). Exposure to bacterial endotoxin lipopolysaccharide (LPS) leads to adipocyte and white adipose tissue (WAT) dysfunction, promoting adipocyte inflammation, decreasing adipogenesis, and inhibiting insulin-induced glucose uptake (Creely et al., 2007; Lu et al., 2008; Osto et al., 2011; Guo et al., 2015).

Cecal ligation and puncture (CLP)-induced sepsis in obese mice results in increased expression of pro-inflammatory cytokines (TNF- $\alpha$ and IL-6) in visceral WAT (Tsujimura et al., 2011; Kutsukake et al., 2014) and decreased circulating adiponectin levels (Kaplan et al., 2016). Adiponectin is the main peptide produced by adipocytes and is involved in an array of metabolic processes, including insulin sensitivity, inflammation, and angiogenesis (Xia et al., 2018). Acute depletion of adiponectin aggravates insulin resistance and hyperlipidemia, as compared to mice with congenital loss of adiponectin (Xia et al., 2018). Hence, decreased adiponectin levels might underlie the insulin resistance that is observed in inflammatory states. Thus, acute inflammation is associated with WAT dysfunction, resulting in a significant reduction in adiponectin levels and insulin resistance, similar as observed in chronic inflammation.

Despite these previous findings in about the negative effect of CLP on WAT, increasing expression of proinflammatory cytokines but decreasing adiponectin (Tsujimura et al., 2011; Kutsukake et al., 2014), to our knowledge, the acute effects of sepsis on metabolic-related pathways in WAT and BAT have not been investigated. In WAT, the main metabolicrelated pathways are composed of genes involved in fatty acid and glucose intake (Fabp4 and Slc2a4), adipogenesis (Adipoq and Pparg), lipogenesis (Fasn, Acaca, and Scd1), lipid droplet development (Plin1), and lipolysis (Prkaca, Mgll, and Lipe) (Klöting and Blüher, 2014; Carobbio et al., 2017). In BAT, the most important metabolic-related genes include those involved thermogenesis (Ucp1, Prdm16, and Dio2), mitochondrial biogenesis and activity (Pgc1a and Cycs), fatty acid and glucose uptake, and lipolysis (Wang et al., 2021). Even though UCP2 does not have the uncoupling potential of UCP1 (Nicholls, 2021), this protein is required to BAT thermogenesis and to the adaptation to cold exposure, by promoting the utilization of non-esterified fatty acids (Nakae et al., 2008; Caron et al., 2017). Full name of these genes is detailed in Table $\mathbf{1}$.

In both WAT and BAT, the good performance of metabolicrelated pathways contributes to whole-body metabolic homeostasis, by ensuring proper lipid storage (WAT) and enhancing energy expenditure and attenuating fat mass gain (BAT) (Klöting and Blüher, 2014; Carobbio et al., 2017; Wang et al., 2021).
TABLE 1 | Description of TaqMan primer/probe sets used in gene expression analysis.

\begin{tabular}{|c|c|c|}
\hline Gene full name & Gene symbol & TaqMan assay reference \\
\hline Interleukin 6 & 116 & Mm00446190_m1 \\
\hline Tumor necrosis factor & Tnf & Mm00443258_m1 \\
\hline $\begin{array}{l}\text { Lipopolysaccharide-binding } \\
\text { protein }\end{array}$ & Lbp & Mm00493139_m1 \\
\hline Lactoferrin & $L t f$ & Mm00434787_m1 \\
\hline $\begin{array}{l}\text { Uncoupling protein } 1 \\
\text { (mitochondrial, proton carrier) }\end{array}$ & Ucp1 & Mm01244861_m1 \\
\hline PR domain containing 16 & Prdm16 & Mm00712556_m1 \\
\hline Cytochrome c, somatic & Cycs & Mm01621048_s1 \\
\hline $\begin{array}{l}\text { Uncoupling protein } 2 \\
\text { (mitochondrial, proton carrier) }\end{array}$ & Ucp2 & Mm00627599_m1 \\
\hline $\begin{array}{l}\text { Deiodinase, iodothyronine, and } \\
\text { type II }\end{array}$ & Dio2 & Mm00515664_m1 \\
\hline $\begin{array}{l}\text { Peroxisome proliferative- } \\
\text { activated receptor, gamma, } \\
\text { and coactivator } 1 \text { alpha }\end{array}$ & Pgc1a & Mm01208835_m1 \\
\hline Aconitase 1 & Aco1 & Mm00801417_m1 \\
\hline $\begin{array}{l}\text { Protein kinase, cAMP- } \\
\text { dependent, catalytic, and } \\
\text { alpha }\end{array}$ & Prkaca & Mm00660092_m1 \\
\hline Lipase, hormone sensitive & Lipe & Mm00495359_m1 \\
\hline Monoglyceride lipase & Mgll & Mm00449274_m1 \\
\hline Fatty acid synthase & Fasn & Mm00662319_m1 \\
\hline $\begin{array}{l}\text { Stearoyl-coenzyme A } \\
\text { desaturase } 1\end{array}$ & Scd1 & Mm00772290_m1 \\
\hline Perilipin 1 & Plin1 & Mm00558672_m1 \\
\hline Leptin & Lep & Mm00434759_m1 \\
\hline $\begin{array}{l}\text { Peroxisome proliferator- } \\
\text { activated receptor gamma }\end{array}$ & Pparg & Mm00440940_m1 \\
\hline Adiponectin & Adipoq & Mm00456425_m1 \\
\hline $\begin{array}{l}\text { Fatty acid-binding protein } 4 \text {, } \\
\text { adipocyte }\end{array}$ & Fabp4 & Mm00445880_m1 \\
\hline $\begin{array}{l}\text { Solute carrier family } 2 \\
\text { (facilitated glucose } \\
\text { transporter), member } 4\end{array}$ & Slc2a4 or Glut4 & Mm01245502_m1 \\
\hline $\begin{array}{l}\text { Acetyl-coenzyme A } \\
\text { carboxylase alpha }\end{array}$ & Acaca & Mm01304258_m1 \\
\hline
\end{tabular}

Here, we hypothesized that acute inflammation associated with CLP-induced sepsis might impact on gene expression markers of metabolic-related pathways in WAT and BAT. To test this hypothesis, in the present study, we aimed to investigate gene expression markers of adipogenesis, lipogenesis, lipid droplet development, fatty acid and glucose uptake, and lipolysis in perirenal white adipose tissue (prWAT) and markers of thermogenesis, mitochondrial biogenesis and activity in BAT in CLP-induced sepsis mouse experimental model.

\section{MATERIALS AND METHODS}

\section{Mice Experiment}

Animals

Adult male C57/Bl6j mice (8-12 weeks old, Charles River, the Netherlands) were housed at a light:dark cycle of $12 \mathrm{~h}: 12 \mathrm{~h}$. Animals were fed ad libitum using standard animal lab chow and drinking water. Experiments were approved by the Central Committee Animal Experiments of the Netherlands (protocol number 16593). 


\section{Animal Experiment}

Animals were anesthetized by subcutaneous injection of xylazine/ketamine $(100 / 10 \mathrm{mg} / \mathrm{kg})$, followed by administration of buprenorphine $(0.1 \mathrm{mg} / \mathrm{kg})$ as analgesic. After confirmation of anesthesia by lack of response to paw pinch and eye reflex, the abdomen was shaved, cleaned, and degermed using a povidone-iodine solution before a $1-\mathrm{cm}$ midline incision was made. The cecum was ligated with a 6-0 suture at half the distance between distal pole and the base of the cecum and punctured once with a 21-gauge needle ('through-and-through' from mesenteric toward antimesenteric direction) which is expected to lead to 'mid-grade' sepsis (Newcomb et al., 1998; Turnbull et al., 2004; Rittirsch et al., 2009). A small amount of stool (2-3 mm) was then extruded to ensure wound patency. The cecum was repositioned, thereby taking care not to spill fecal material on the wound edges, followed by closure of the abdomen by running sutures to the abdominal musculature (6-0 Safil sutures) and short interrupted sutures to the skin (5-0 Safil), as described by Rittirsch et al., 2009. Next, $1 \mathrm{ml}$ of saline (warmed, $0.9 \% \mathrm{NaCl}$ s.c.) was administered to compensate for the expected relative volume depletion due to the onset of sepsis. Following the procedure, mice recovered at $26-28^{\circ} \mathrm{C}$ for $2 \mathrm{~h}$. Broad-spectrum antibiotics (imipenem/cilastatin, $100 \mathrm{mg} / \mathrm{kg}$ s.c.) were administered at $2-10 \mathrm{~h}$ following surgery, while analgesics (buprenorphine, $0.1 \mathrm{mg} / \mathrm{kg}$ body weight, s.c.) were administered perioperatively. A group of operated animals, in which the cecum was located but not punctured, served as sham. In addition, a group of animals were included that underwent time-matched anesthesia, but no surgery and served as controls. Animals were euthanized at $24 \mathrm{~h}$ after surgery. Upon euthanization, $40 \mu \mathrm{l}$ of blood was used to obtain a blood cell counts on a Sysmex PoCH 100 -iv analyzer hematocytometer. In addition, a blood smear was Giemsa-stained to confirm the data from the hematocytometer and manually obtain differential blood cell counts. The remainder of the EDTA-anticoagulated blood was separated into plasma by centrifugation at $1,600 \mathrm{~g}$ for $10 \mathrm{~min}$ and serum by allowing it to clot for $30 \mathrm{~min}$ followed by centrifugation at $3,000 \mathrm{~g}$ for $10 \mathrm{~min}$. Plasma, serum, and interscapular BAT and prWAT were snap-frozen in liquid nitrogen for further analysis.

\section{Measurement of Cytokines}

To determine the extent of inflammation and assess the severity of sepsis, plasma levels of TNF- $\alpha$ and IL- 6 were measured, in addition to changes in body weight, temperature, and leukocyte counts. Mouse DuoSet ELISAs were used to measure plasma cytokine levels (DY410 and DY406; RnD Systems), according to the manufacturer's instructions. Briefly, ELISA plates (DY990, RnD Systems) were coated overnight with the capture antibody diluted in $100 \mu \mathrm{l} \mathrm{PBS}$. Plates were washed three times with wash buffer $\left(0.05 \%\right.$ Tween ${ }^{\circledR}$ 20 in PBS; $137 \mathrm{mM} \mathrm{NaCl}, 2.7 \mathrm{mM} \mathrm{KCl}, 8.1 \mathrm{mM} \mathrm{Na}_{2} \mathrm{HPO}_{4}$, $1.5 \mathrm{mM} \mathrm{KH} \mathrm{KO}_{4}, \mathrm{pH}$ 7.2-7.4), followed by blocking by incubating the wells for $1 \mathrm{~h}$ with $300 \mu \mathrm{l}$ of reagent diluent
( $1 \%$ probumin $\mathrm{w} / \mathrm{v}$ in $\mathrm{PBS}$ ). Washing was repeated, and samples were added to the wells. Plasma samples were diluted $10 \mathrm{x}$ for TNF- $\alpha$, and $100 \mathrm{x}$ for IL- 6 in $100 \mu \mathrm{l}$ reagent diluent, to obtain an $\mathrm{OD}$ value within the measurement range as described by the manufacturer. After incubation for $2 \mathrm{~h}$ at room temperature, wells were washed, followed by adding $100 \mu \mathrm{l}$ of detection antibody diluted in reagent diluent to each well. Again, plates were left to incubate for $2 \mathrm{~h}$ at room temperature, followed by washing. Finally, $100 \mu \mathrm{l}$ of substrate solution (DY999, RnD Systems) was added, and after $20 \mathrm{~min}$ incubating in the dark, $50 \mu \mathrm{l}$ stop solution (2 $\mathrm{M} \mathrm{H}_{2} \mathrm{SO}_{4}$ ) was added. The optical density (OD) was measured using a microplate reader set to $450 \mathrm{~nm}$, while readings at $540 \mathrm{~nm}$ were subtracted as correction to increase accuracy.

\section{RNA Analysis}

RNA purification was performed using the RNeasy Lipid Tissue Mini Kit (QIAgen, Izasa SA, Barcelona, Spain), and the integrity was checked with the Agilent Bioanalyzer. Gene expression was assessed by real-time polymerase chain reaction (PCR) using a LightCycler 480 Real-Time PCR System (Roche Diagnostics SL, Barcelona, Spain), with TaqMan technology suitable for relative genetic expression quantification. The real-time PCR was performed in a final volume of $12 \mu \mathrm{l}$. The cycle program consisted of an initial denaturing for $10 \mathrm{~min}$ at $95^{\circ} \mathrm{C}, 40$ consecutive 15 -min cycles of denaturizing at $95^{\circ} \mathrm{C}$, and a $1-\mathrm{min}$ annealing and extension phase at $60^{\circ} \mathrm{C}$. A threshold cycle (Ct value) was obtained for each amplification curve, and a DeltaCt value was first calculated by subtracting the Ct value eukaryotic $18 \mathrm{~S}$ rRNA endogenous control RNA from the Ct value for each sample. Fold changes compared with the endogenous control were then determined by calculating 2-DeltaCt, so that gene expression results are expressed as expression ratio relative to eukaryotic $18 \mathrm{~S}$ gene expression according to the manufacturer's guidelines.

The primer/probe sets used are detailed in Table $\mathbf{1}$.

\section{Statistical Analysis}

Statistical analyses were performed using SPSS 12.0 software for Windows (IBM Inc., Armonk, New York, United States) and analyzed using nonparametric tests (Mann-Whitney $U$ test). Data are expressed as mean \pm standard error of the mean. $p<0.05$ was considered statistically significant different. Figures were made with GraphPad Prism version 5.00 for Windows (GraphPad Software, San Diego, United States).

\section{RESULTS}

To validate the induction of acute inflammation in our model of sepsis, we first measured biomarkers of inflammation. CLP-induced sepsis led to excessive loss of body weight, lower body temperature, and decreased number of circulating leukocytes. Plasma levels of circulating pro-inflammatory cytokines were increased at $24 \mathrm{~h}$ after induction (Figures 1A-G). 
A

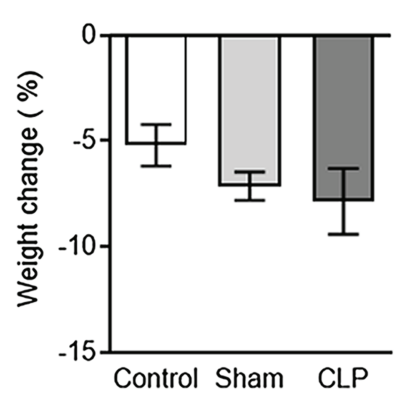

D

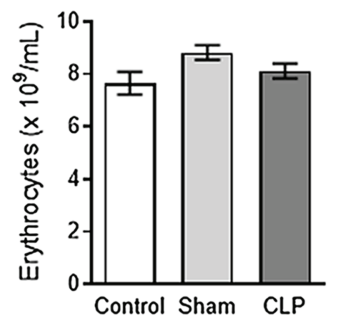

E

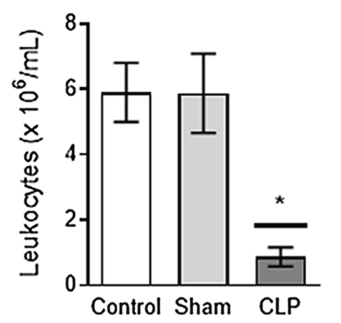

B

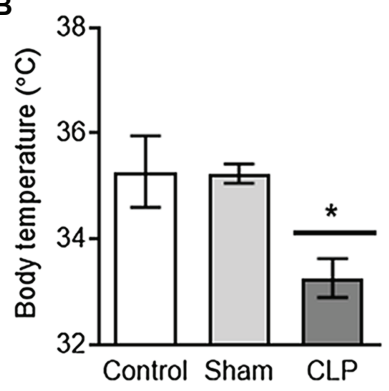

F
C

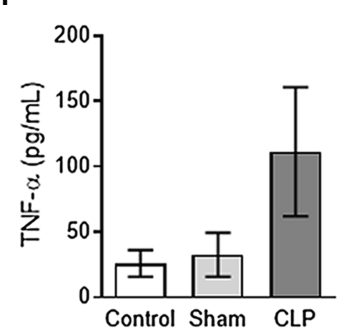

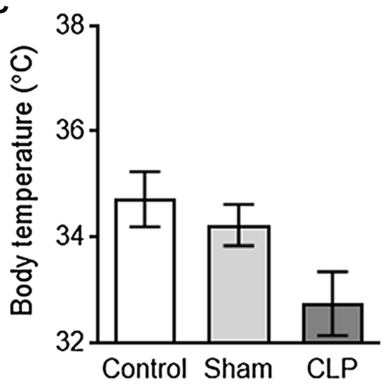

G

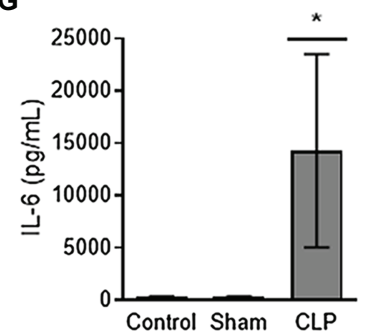

FIGURE 1 | (A-C) Sepsis leads to transient hypothermia. Mice in cecal ligation and puncture (CLP) seem to experience weight loss, which was, however, not different compared to control or sham (A). The body temperature after induction of sepsis CLP was transiently reduced at $8 \mathrm{~h}$ after induction as compared to control and Sham (B). Upon euthanization (24 h after induction), no differences were observed in body temperatures (C). (D,E) Sepsis is associated with profound leukopenia. The numbers of erythrocytes (D) were not affected by sepsis CLP or Sham surgery. Further, sepsis CLP was associated with clearance of the majority of circulating leukocytes (E). (F,G) Sepsis leads to increased plasma levels of proinflammatory cytokines. The induction of sepsis CLP tended to increase the level of TNF- $\alpha$ in plasma (F) and induced a profound rise in plasma IL-6 levels (G). CLP: cecal ligation and puncture. * means $p<0.05, n=7-8$ mice per group.

\section{Effects of CLP-Induced Sepsis on Perirenal White Adipose Tissue}

In prWAT, CLP-induced sepsis resulted in increased expression of proinflammatory ( $T n f$, Il6, and $L t f$ )-related gene expression (Figure 2A) in parallel to decreased adipogenesis (Adipoq, Pparg, Plin1, Slc2a4, Fabp4, and Lep)-, lipolytic/browning (Prkaca, Mgll, Lipe, and Prdm16)-related gene expression (Figures 2B,C), but did not exert any effects on expression of Pgcla and lipogenic (Scd1, Acaca, and Fasn)-related genes (Figures 2C,D). Thus, similar to previous studies (Tsujimura et al., 2011; Kutsukake et al., 2014), sepsis led to the induction of genes encoding pro-inflammatory cytokines in WAT, associated with decreased expression of genes related to adipogenesis. In addition, CLP-induced sepsis also attenuated catabolic pathways, reducing expression of Prdm16 and lipolysis-related genes.

\section{Effects of CLP-Induced Sepsis on Interscapular Brown Adipose Tissue-Related Gene Expression}

To assess whether acute inflammation in sepsis leads to BAT inflammation and affects BAT function similar to WAT, we then measured expression of genes encoding pro-inflammatory cytokines and related to adipose tissue function in BAT. CLP-induced sepsis resulted in increased Il6, Ltf, and Lbp but not Tnf in BAT (Figure 3A). In contrast to WAT, no differences were found on gene expression markers of BAT activity, including thermogenic/mitochondrial (Ucp1, Prdm16, Ucp2, Cycs, Pgc1a, Aco1, and Dio2)- and lipolytic (Prkaka, Mgll, Lipe, and
Plin1)-related genes, and markers of fatty acid and glucose uptake (Fabp4 and Slc2a4; Figures 3B,C). Thus, although sepsis also led to expression of pro-inflammatory cytokines, it was not associated with markers of adipose tissue dysfunction in BAT.

\section{DISCUSSION}

The current study confirms the effects of acute inflammation on adipose tissue dysfunction in perirenal (visceral) WAT, whereas in BAT, the effects of CLP-induced sepsis were less profound.

In prWAT, the main effects of CLP-induced sepsis included increased expression of proinflammatory cytokines (Tnf and $I L-6$ ) and a neutrophil marker $(L t f)$ and decreased markers of adipogenesis. The expression of $T n f$ and $I L-6$ genes is widely used to characterize sepsis-induced inflammatory response in several tissues (Tsujimura et al., 2011; Chen et al., 2014; Ferlito et al., 2014; Kutsukake et al., 2014; Li et al., 2017). Even though IL-6 (Hoch et al., 2008) is expressed in adipocytes, the main biosynthesis source of IL-6 and TNF in adipose tissue is in cells of stromal vascular fraction (SVF; Almuraikhy et al., 2016). In normal conditions, Ltf gene was more expressed in adipocytes compared to SVF (Moreno-Navarrete et al., 2013) and an adipogenic role of Ltf has been demonstrated (Moreno-Navarrete et al., 2011, 2014). However, the most abundant expression of $\mathrm{Ltf}$ is found in neutrophils (Baker and Baker, 2005), which is a 100-fold higher as compared to adipose tissue (Moreno-Navarrete et al., 2013). In addition, inflammatory conditions decrease adipocyte $L t f \mathrm{mRNA}$ 


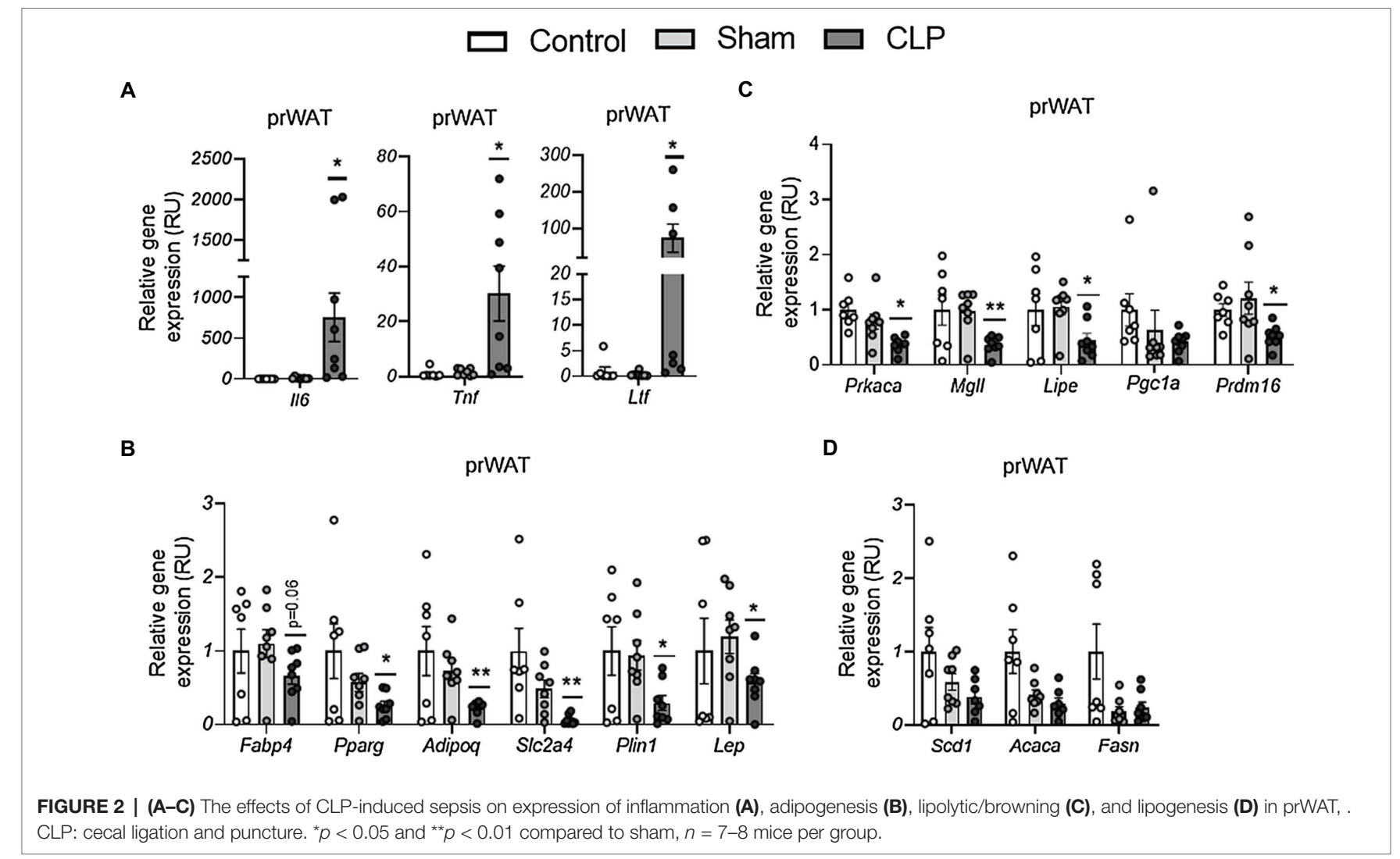

(Yarmo et al., 2010) but increase neutrophil Ltf (Bae et al., 2014). These findings suggest that increased Ltf mRNA might result from enhanced neutrophil infiltration in adipose tissue in response to CLP-induced sepsis. This hypothesis is further supported by the severe decrease in the number of leukocytes in plasma in the septic mice.

Considering the negative effects of acute inflammation in adipocyte physiology and adipogenesis previously demonstrated at cellular level (Constant et al., 2006; Lacasa et al., 2007; Yarmo et al., 2010), the sepsis-induced inflammatory environment might explain the observed decreased adipogenesis.

In BAT, the rise of $L B P$ mRNA was the most significant effect of CLP-induced sepsis. Interestingly, a recent study demonstrated decreased expression of $L B P$ in cold-induced BAT and increased BAT activity in Lbp-null mice, suggesting that LBP was a negative regulator of the browning process (Gavaldà-Navarro et al., 2016). In the current study, increased LBP gene expression was not associated with a significant decrease in thermogenic or mitochondrial-related genes.

Even though in vitro experiments demonstrated that macrophage conditioned medium attenuated cold-induced brown adipocyte activity (Kern et al., 2014) and that the activation of receptors that mediate LPS pathway (such as TLR4, TLR2, and NOD1) inhibited UCP1 and mitochondrial respiration in brown adipocytes (Bae et al., 2014), in the present study, no significant effects of CLP-induced sepsis in expression of thermogenic and mitochondrial activity-related genes were observed.
In fact, the impact of inflammation on BAT activity is currently discussed, as some studies in mice with obesityassociated chronic low-level inflammation reported that BAT inflammation is associated with decreased thermogenic activity (Sakamoto et al., 2016; Escalona-Garrido et al., 2020), in other studies no correlation between BAT thermogenesis and inflammation was observed (Cao et al., 2018; Boulet et al., 2021). To the best of our knowledge, the in vivo effects of acute inflammation mediated by CLP-induced sepsis in expression of BAT thermogenic- and metabolic-related genes have not been previously reported.

Interestingly, comparing the induction of inflammation-related genes in prWAT and BAT, we found that Tnf gene expression was only induced in prWAT. TNF $\alpha$ induces insulin resistance promoting the phosphorylation of serine residues in insulin receptor substrate 1 (Hotamisligil et al., 1996). The specific increased Tnf gene expression in prWAT points to this cytokine as a possible mediator of WAT dysfunction through the impairment of insulin action in adipocytes. In BAT, the absence of changes in Tnf mRNA levels run in parallel to the absence of negative effects of CLP-induced sepsis on metabolic-related gene expression. In fact, the induction of Tnf mRNA in BAT enhanced lipogenic gene expression, resulting in BAT "whitening," whereas the inhibition of this cytokine led to increased expression of lipolytic and thermogenic genes (Polyák et al., 2016).

To sum up, current data show that whereas CLP-induced sepsis promotes both WAT and BAT inflammation, this acute inflammatory condition only impacts on WAT adipogenic gene 


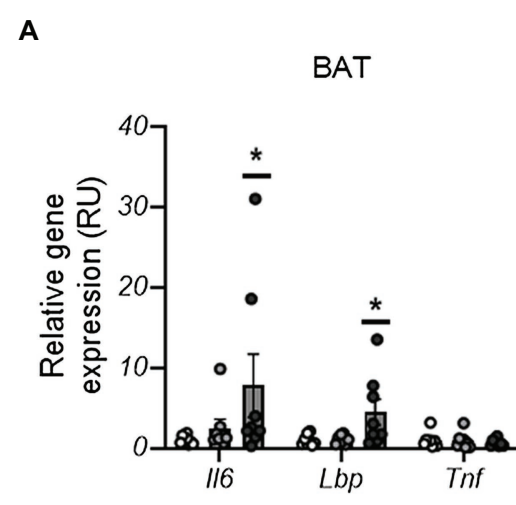

B

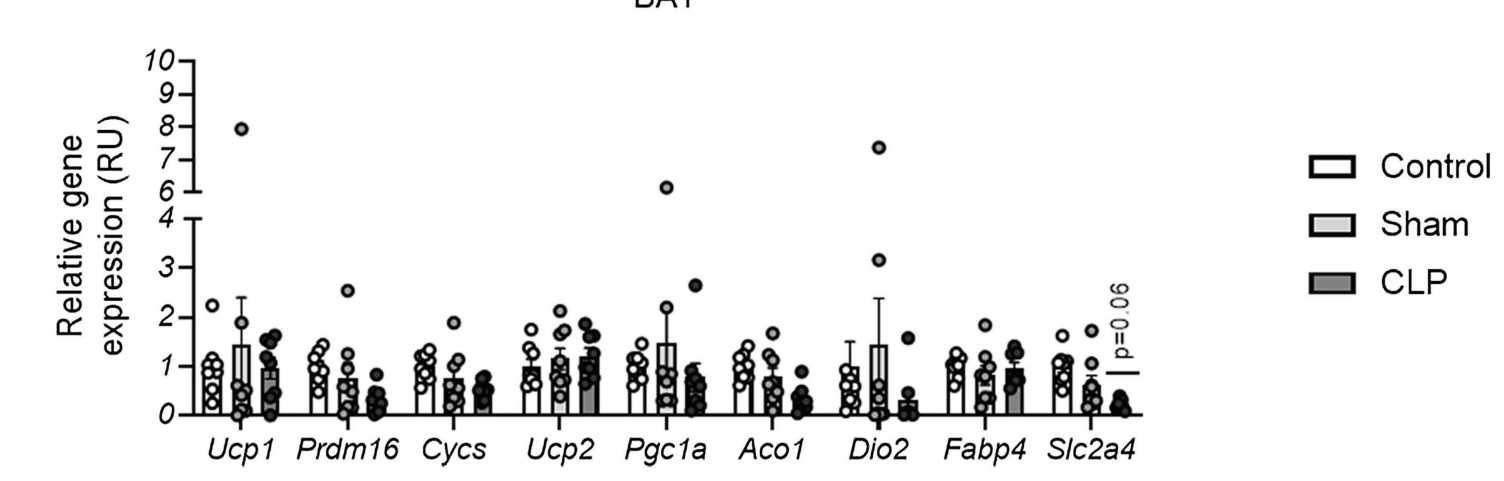

C

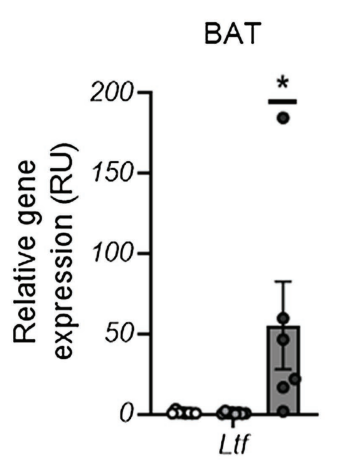

BAT

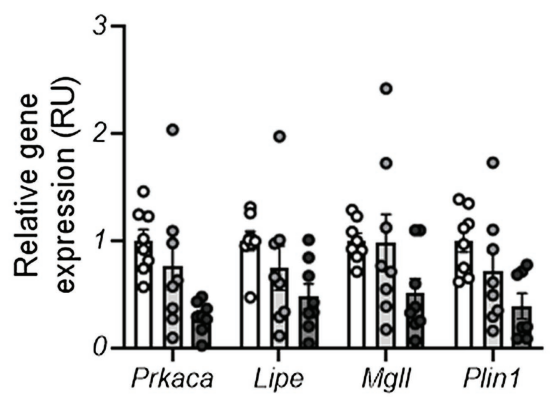

FIGURE 3 | (A-C) The effects of CLP-induced sepsis on expression of inflammation (A), thermogenesis/mitochondria (B), and lipolysis (C)-related genes in BAT, . CLP: cecal ligation and puncture. ${ }^{*} p<0.05$ and ${ }^{* *} p<0.01$ compared to sham, $n=7-8$ mice per group.

expression, without significant effects on BAT thermogenic genes, suggesting a dissociation of acute inflammation from adipose tissue dysfunction in BAT, but not WAT. However, since current study was based only on gene expression analysis, further functional experiments are required to confirm this suggestion.

\section{DATA AVAILABILITY STATEMENT}

The raw data supporting the conclusions of this article will be made available by the authors, without undue reservation.

\section{ETHICS STATEMENT}

The animal study was reviewed and approved by the Central Committee Animal Experiments of Netherlands (protocol number 16593).

\section{REFERENCES}

Acosta, J. R., Douagi, I., Andersson, D. P., Bäckdahl, J., Rydén, M., Arner, P., et al. (2016). Increased fat cell size: a major phenotype of subcutaneous white adipose tissue in non-obese individuals with type 2 diabetes. Diabetologia 59, 560-570. doi: 10.1007/s00125-015-3810-6

\section{AUTHOR CONTRIBUTIONS}

JMM-N and $\mathrm{HB}$ participated in study design and analysis of data, and wrote and edited the manuscript. FC, VJ, and JMF-R participated in analysis of data, and revised the manuscript critically for important intellectual content. All authors contributed to the article and approved the submitted version.

\section{FUNDING}

This work was partially supported by research grants PI16/01173 and PI19/01712 from the Instituto de Salud Carlos III and Fondo Europeo de Desarrollo Regional (FEDER). CIBEROBN Fisiopatología de la Obesidad y Nutrición is an initiative from the Instituto de Salud Carlos III. Additionally, the work is supported by a Kolff Junior Postdoc grant 16OKG06 from the Dutch Kidney Foundation and a Mandema Stipend from the University Medical Center Groningen awarded to HB.

Almuraikhy, S., Kafienah, W., Bashah, M., Diboun, I., Jaganjac, M., Al-Khelaifi, F., et al. (2016). Interleukin-6 induces impairment in human subcutaneous adipogenesis in obesity-associated insulin resistance. Diabetologia 59, 2406-2416. doi: 10.1007/s00125-016-4031-3

Bae, J., Ricciardi, C. J., Esposito, D., Komarnytsky, S., Hu, P., Curry, B. J., et al. (2014). Activation of pattern recognition receptors in brown adipocytes 
induces inflammation and suppresses uncoupling protein 1 expression and mitochondrial respiration. Am. J. Phys. Cell Phys. 306, C918-C930. doi: 10.1152/ajpcell.00249.2013

Baker, E. N., and Baker, H. M. (2005). Molecular structure, binding properties and dynamics of lactoferrin. Cell. Mol. Life Sci. 62, 2531-2539. doi: 10.1007/ s00018-005-5368-9

Boulet, N., Luijten, I. H., Cannon, B., and Nedergaard, J. (2021). Thermogenic recruitment of brown and brite/beige adipose tissues is not obligatorily associated with macrophage accretion or attrition. Am. J. Physiol. Metab. 320, E359-E378. doi: 10.1152/ajpendo.00352.2020

Cao, J., Zhu, Q., Liu, L., Glazier, B. J., Hinkel, B. C., Liang, C., et al. (2018). Global transcriptome analysis of brown adipose tissue of diet-induced obese mice. Int. J. Mol. Sci. 19:1095. doi: 10.3390/ijms19041095

Carobbio, S., Pellegrinelli, V., and Vidal-Puig, A. (2017). "Adipose tissue function and expandability as determinants of lipotoxicity and the metabolic syndrome," in Advances in Experimental Medicine and Biology (New York: Springer LLC), 161-196.

Caron, A., Labbé, S. M., Carter, S., Roy, M. C., Lecomte, R., Ricquier, D., et al. (2017). Loss of UCP2 impairs cold-induced non-shivering thermogenesis by promoting a shift toward glucose utilization in brown adipose tissue. Biochimie 134, 118-126. doi: 10.1016/j.biochi.2017.01.006

Chen, X., Xu, W., Wang, Y., Luo, H., Quan, S., Zhou, J., et al. (2014). Hydrogen sulfide reduces kidney injury due to urinary-derived sepsis by inhibiting NF- $\mathrm{KB}$ expression, decreasing TNF- $\alpha$ levels and increasing IL-10 levels. Exp. Ther. Med. 8, 464-470. doi: 10.3892/etm.2014.1781

Constant, V. A., Gagnon, A., Landry, A., and Sorisky, A. (2006). Macrophageconditioned medium inhibits the differentiation of 3T3-L1 and human abdominal preadipocytes. Diabetologia 49, 1402-1411. doi: 10.1007/ s00125-006-0253-0

Creely, S. J., McTernan, P. G., Kusminski, C. M., Fisher, F. M., Da Silva, N. F., Khanolkar, M., et al. (2007). Lipopolysaccharide activates an innate immune system response in human adipose tissue in obesity and type 2 diabetes. Am. J. Physiol. Endocrinol. Metab. 292, E740-E747. doi: 10.1152/ ajpendo.00302.2006

Escalona-Garrido, C., Vázquez, P., Mera, P., Zagmutt, S., García-Casarrubios, E., Montero-Pedrazuela, A., et al. (2020). Moderate SIRT1 overexpression protects against brown adipose tissue inflammation. Mol. Metab. 42:101097. doi: 10.1016/j.molmet.2020.101097

Ferlito, M., Wang, Q., Fulton, W. B., Colombani, P. M., Marchionni, L., Fox-Talbot, K., et al. (2014). $\mathrm{H}_{2} \mathrm{~S}$ increases survival during sepsis: protective effect of CHOP inhibition. J. Immunol. 192, 1806-1814. doi: 10.4049/ jimmunol.1300835

Gavaldà-Navarro, A., Moreno-Navarrete, J. M., Quesada-López, T., Cairó, M., Giralt, M., Fernández-Real, J. M., et al. (2016). Lipopolysaccharide-binding protein is a negative regulator of adipose tissue browning in mice and humans. Diabetologia 59, 2208-2218. doi: 10.1007/s00125-016-4028-y

Guo, J., Liu, Z., Sun, H., Huang, Y., Albrecht, E., Zhao, R., et al. (2015). Lipopolysaccharide challenge significantly influences lipid metabolism and proteome of white adipose tissue in growing pigs. Lipids Health Dis. 14:68. doi: 10.1186/s12944-015-0067-5

Hoch, M., Eberle, A. N., Peterli, R., Peters, T., Seboek, D., Keller, U., et al. (2008). LPS induces interleukin-6 and interleukin-8 but not tumor necrosis factor- $\alpha$ in human adipocytes. Cytokine 41, 29-37. doi: 10.1016/j.cyto.2007.10.008

Hotamisligil, G. S. (2017). Inflammation, metaflammation and immunometabolic disorders. Nature 542, 177-185. doi: 10.1038/nature21363

Hotamisligil, G. S., Peraldi, P., Budavari, A., Ellis, R., White, M. F., and Spiegelman, B. M. (1996). IRS-1-mediated inhibition of insulin receptor tyrosine kinase activity in TNF-alpha- and obesity-induced insulin resistance. Science 271, 665-668. doi: 10.1126/science.271.5249.665

Kaplan, J. M., Nowell, M., Lahni, P., Shen, H., Shanmukhappa, S. K., and Zingarelli, B. (2016). Obesity enhances sepsis-induced liver inflammation and injury in mice. Obesity 24, 1480-1488. doi: 10.1002/oby.21504

Kern, P. A., Finlin, B. S., Zhu, B., Rasouli, N., McGehee, R. E., Westgate, P. M., et al. (2014). The effects of temperature and seasons on subcutaneous white adipose tissue in humans: evidence for thermogenic gene induction. J. Clin. Endocrinol. Metab. 99, E2772-E2779. doi: 10.1210/jc.2014-2440

Klöting, N., and Blüher, M. (2014). Adipocyte dysfunction, inflammation and metabolic syndrome. Rev. Endocr. Metab. Disord. 15, 277-287. doi: 10.1007/ s11154-014-9301-0
Kutsukake, M., Matsutani, T., Tamura, K., Matsuda, A., Kobayashi, M., Tachikawa, E., et al. (2014). Pioglitazone attenuates lung injury by modulating adipose inflammation. J. Surg. Res. 189, 295-303. doi: 10.1016/j.jss.2014.03.007

Lacasa, D., Taleb, S., Keophiphath, M., Miranville, A., and Clement, K. (2007). Macrophage-secreted factors impair human adipogenesis: involvement of proinflammatory state in preadipocytes. Endocrinology 148, 868-877. doi: 10.1210/en.2006-0687

Li, X., Cheng, Q., Li, J., He, Y., Tian, P., and Xu, C. (2017). Significance of hydrogen sulfide in sepsis-induced myocardial injury in rats. Exp. Ther. Med. 14, 2153-2161. doi: 10.3892/etm.2017.4742

Lu, B., Lu, Y., Moser, A. H., Shigenaga, J. K., Grunfeld, C., and Feingold, K. R. (2008). LPS and proinflammatory cytokines decrease lipin-1 in mouse adipose tissue and 3T3-L1 adipocytes. Am. J. Physiol. Endocrinol. Metab. 295:E1502. doi: 10.1152/ajpendo.90323.2008

Moreno-Navarrete, J. M., Ortega, F., Moreno, M., Serrano, M., Ricart, W., and Fernández-Real, J. M. (2014). Lactoferrin gene knockdown leads to similar effects to iron chelation in human adipocytes. J. Cell. Mol. Med. 18, 391-395. doi: $10.1111 / \mathrm{jcmm} .12234$

Moreno-Navarrete, J. M., Ortega, F., Sabater, M., Ricart, W., and Fernández-Real, J. M. (2011). Proadipogenic effects of lactoferrin in human subcutaneous and visceral preadipocytes. J. Nutr. Biochem. 22, 1143-1149. doi: $10.1016 /$ j.jnutbio.2010.09.015

Moreno-Navarrete, J. M., Serrano, M., Sabater, M., Ortega, F., Serino, M., Pueyo, N., et al. (2013). Study of lactoferrin gene expression in human and mouse adipose tissue, human preadipocytes and mouse 3T3-L1 fibroblasts. J. Nutr. Biochem. 24, 1266-1275. doi: 10.1016/j.jnutbio.2012.10.002

Nakae, J., Cao, Y., Oki, M., Orba, Y., Sawa, H., Kiyonari, H., et al. (2008). Forkhead transcription factor FoxO1 in adipose tissue regulates energy storage and expenditure. Diabetes 57, 563-576. doi: 10.2337/db070698

Newcomb, D., Bolgos, G., Green, L., and Remick, D. G. (1998). Antibiotic treatment influences outcome in murine sepsis: mediators of increased morbidity. Shock 10, 110-117. doi: 10.1097/00024382-199808000-00005

Nicholls, D. G. (2021). Mitochondrial proton leaks and uncoupling proteins. Biochim. Biophys. Acta Bioenerg. 1862:148428. doi: 10.1016/j.bbabio.2021.148428

Ortega, F. J., Vilallonga, R., Xifra, G., Sabater, M., Ricart, W., and Fernández-Real, J. M. (2016). Bariatric surgery acutely changes the expression of inflammatory and lipogenic genes in obese adipose tissue. Surg. Obes. Relat. Dis. 12, 357-362. doi: 10.1016/j.soard.2015.08.498

Osto, M., Zini, E., Franchini, M., Wolfrum, C., Guscetti, F., Hafner, M., et al. (2011). Subacute endotoxemia induces adipose inflammation and changes in lipid and lipoprotein metabolism in cats. Endocrinology 152, 804-815. doi: 10.1210/en.2010-0999

Polyák, Á., Winkler, Z., Kuti, D., Ferenczi, S., and Kovács, K. J. (2016). Brown adipose tissue in obesity: fractalkine-receptor dependent immune cell recruitment affects metabolic-related gene expression. Biochim. Biophys. Acta 1861, 1614-1622. doi: 10.1016/j.bbalip.2016.07.002

Rittirsch, D., Huber-Lang, M. S., Flierl, M. A., and Ward, P. A. (2009). Immunodesign of experimental sepsis by cecal ligation and puncture. Nat. Protoc. 4, 31-36. doi: 10.1038/nprot.2008.214

Sakamoto, T., Nitta, T., Maruno, K., Yeh, Y. S., Kuwata, H., Tomita, K., et al. (2016). Macrophage infiltration into obese adipose tissues suppresses the induction of UCP1 level in mice. Am. J. Phys. Endocrinol. Metab. 310, E676-E687. doi: 10.1152/ajpendo.00028.2015

Tsujimura, Y., Matsutani, T., Matsuda, A., Kutsukake, M., Uchida, E., Sasajima, K., et al. (2011). Effects of pioglitazone on survival and omental adipocyte function in mice with sepsis induced by cecal ligation and puncture. J. Surg. Res. 171, e215-e221. doi: 10.1016/j.jss.2011.08.012

Turnbull, I. R., Javadi, P., Buchman, T. G., Hotchkiss, R. S., Karl, I. E., and Coopersmith, C. M. (2004). Antibiotics improve survival in sepsis independent of injury severity but do not change mortality in mice with markedly elevated interleukin 6 levels. Shock 21, 121-125. doi: 10.1097/01. shk.0000108399.56565.e7

Wang, Z., Wang, Q. A., Liu, Y., and Jiang, L. (2021). Energy metabolism in brown adipose tissue. FEBS J. doi: 10.1111/febs.16015 [Epub ahead of print]

Xia, J. Y., Sun, K., Hepler, C., Ghaben, A. L., Gupta, R. K., An, Y. A., et al. (2018). Acute loss of adipose tissue-derived adiponectin triggers immediate metabolic deterioration in mice. Diabetologia 61, 932-941. doi: 10.1007/ s00125-017-4516-8 
Yarmo, M. N., Gagnon, A., and Sorisky, A. (2010). The anti-adipogenic effect of macrophage-conditioned medium requires the IKK $\beta / N F-\kappa B$ pathway. Horm. Metab. Res. 42, 831-836. doi: 10.1055/s-0030-1263124

Conflict of Interest: The authors declare that the research was conducted in the absence of any commercial or financial relationships that could be construed as a potential conflict of interest.
Copyright (C) 2021 Moreno-Navarrete, Comas, de Jager, Fernández-Real and Bouma. This is an open-access article distributed under the terms of the Creative Commons Attribution License (CC BY). The use, distribution or reproduction in other forums is permitted, provided the original author(s) and the copyright owner(s) are credited and that the original publication in this journal is cited, in accordance with accepted academic practice. No use, distribution or reproduction is permitted which does not comply with these terms. 